\title{
Rancang Bangun Sistem Komunikasi Data Pemesanan pada Drive Thru Toko Roti ETU Polinema Berbasis Android
}

\author{
Dwika Rahman Irianto ${ }^{1}$, Moh. Abdullah Anshori ${ }^{2}$, Putri Elfa Mas'udi ${ }^{3}$ \\ ${ }^{1,2}$ Program Studi Jaringan Telekomunikasi Digital, Teknik Elektro, Politeknik Negeri Malang, Indonesia \\ ${ }^{3}$ Program Studi Teknik Telekomunikasi, Teknik Elektro, Politeknik Negeri Malang, Indonesia \\ 1wikarahman31@gmail.com, ㄹabdullah.anshori@polinema.ac.id, ${ }^{3}$ putri.elfa@ polinema.ac.id
}

\begin{abstract}
The rapid development of technology increases the competitive power of the business world which is getting bigger. This technology has information and communication systems that are easily accessible by the internet. In a restaurant / shop has different ordering systems. Drive thru is a service that is considered a modern system, consumers can easily order food or drinks even though they are still in the vehicle and do not need to enter the store. In the drive thru ordering system, consumers come to the intended shop and can order food from the vehicle without the need to enter the restaurant, where the order is ordered directly in front of the microphone outlet which is connected to the cashier specifically for drive thru consumers and if so, consumers can continue. to the cashier to make payments and take orders. In this study, a food ordering system is proposed for the drive thru store, by making an application and web admin where consumers can place orders quickly, and there is also Qrcode which functions as a sign of user purchases and Epay's balance which simplifies the payment process. Web functions as admin data. The test results can be concluded that the Qrcode detection on Qrcode scanner has an average reading accuracy at a distance of $2.98 \mathrm{~cm}$, in the Qos test which is carried out with different networks, the result is that the Telkomsel provider gets the smallest delay with a value of 0.121766.
\end{abstract}

Keywords - QoS, Qrcode, Drive Thru, Booking System, Android.

Abstrak - Perkembangan teknologi semakin pesat menambah daya persaingan dalam dunia bisnis yang semakin besar, teknologi ini terdapat sistem informasi dan komunikasi yang mudah diakses dengan adanya internet. Dalam sebuah restoran / toko memiliki sistem pemesanan yang berbeda- beda. Drive thru merupakan sebuah layanan yang dianggap sebuah sistem modern, konsumen dapat dengan mudah memesan makanan ataupun minuman walau masih berada didalam kendaraan dan tidak perlu masuk kedalam toko. Dalam sistem pemesanan drive thru konsumen datang ke toko yang dituju lalu dapat memesan sebuah makanan dari kendaraan tanpa perlu masuk kedalam restoran, dimana cara pemesanannya memesan secara langsung didepan gerai mikrofon yang sudah terhubung ke kasir khusus untuk konsumen drive thru dan jika sudah, konsumen dapat melanjutkan ke kasir untuk melakukan pembayaran serta pengambilan pesanan. Pada penelitian ini diusulkan sistem pemesanan makanan pada drive thru toko, dengan membuatkan aplikasi dan web admin dimana konsumen dapat melakukan pemesanan dengan cepat, serta terdapat juga Qrcode yang berfungsi sebagai tanda pembelian user dan saldo Epay yang mempermudah proses pembayaran. Web berfungsi sebagai data admin. Hasil pengujian dapat disimpulkan bahwa deteksi Qrcode pada Qrcode scanner memiliki rata-rata akurat baca pada jarak $2,98 \mathrm{~cm}$, dalam uji Qos yang dilakukan dengan berbeda jaringan, hasilnya dimana provider telkomsel mendapat delay terkecil dengan nilai 0.121766 .

Kata kunci-QoS, Qrcode, Drive Thru, Sistem Pemesanan, Android.

\section{PENDAHULUAN}

Perkembangan teknologi yang semakin pesat ini juga menambah daya persaingan dalam dunia bisnis yang semakin besar, teknologi ini terdapat sistem informasi dan komunikasi yang mudah diakses dengan adanya internet. Internet sendiri merupakan sebuah jaringan komputer yang dapat terhubung antara jaringan jaringan 1 dan jaringan yang lain dimana dengan hal itu menjadikan sebuah sistem komunikasi dua arah ataupun lebih, Komunikasi data merupakan sebuah proses pengiriman dan penerimaan data/informasi dari 2 ataupun lebih alat. sebuah teknologi informasi dan komunikasi yang berkembang sekarang memaksa banyak faktor untuk ikut berkembang. Rumah makan / Toko adalah istilah umum untuk sebuah usaha yang menjual makanan/ kepada masyarakat dan menyediakan tempat untuk menikmati hidangan itu, serta menetapkan tarif tertentu untuk makanan dan pelayanannya.

Pemakaian teknologi internet pada saat ini telah banyak digunakan oleh masyarakat untuk mebuat usaha kecil ataupun menengah [1][2].

Entrepeneurship Training Unit / ETU polinema merupakan sebuah unit pengelola kewirausahaan yang bertugas memfasilitasi semua kegiatan kewirausahaan mahasiswa yang terdiri dari pendidikan, pelatihan, seminar, pemberian modal usaha, konsultasi hingga pendampingan usaha. ETU polinema berdiri pada 23 agustus 2006 Seiring dengan berjalannya waktu, kegiatan yang di kelola ETU semakin luas. Saat ini ETU polinema memiliki sebuah usaha kecil yang menjual beraneka ragam roti isi yang berada di kantin polinema lantai 2. Sistem pemesanan saat ini harus datang terlebih dahulu ke toko setelah itu baru dapat memilih roti [3]. 
Dalam sebuah restoran / toko memiliki sistem pemesanan yang berbeda- beda, tetapi sekarang terdapat sistem pemesanan baru yang bernama drive thru. Drive Thru merupakan sebuah layanan yang dianggap sebuah sistem yang modern , dimana konsumen bisa dengan mudah memesan sebuah makanan ataupun minuman walau masih berada didalam kendaraan dan tidak perlu masuk kedalam toko. Dalam sistem pemesanan drive thru konsumen datang ke toko yang dituju lalu dapat memesan sebuah makanan dari kendaraan tanpa perlu masuk kedalam restoran, dimana cara pemesanannya memesan secara langsung didepan gerai mikrofon yang sudah terhubung ke kasir khusus untuk konsumen drivethru dan jika sudah, konsumen dapat melanjutkan ke kasir untuk melakukan pembayaran serta pengambilan pesanan, sistem pemesanan drive thru memiliki beberapa kelemahan dimana konsumen akan sulit memilih produk dikarenakan menu yang tidak terdapat pada gerai luar toko dan dengan itu dapat memperlama jumlah antrian [4].

Dari permasalahan yang sudah dijelaskan di atas tadi, perlu adanya sebuah sistem informasi yang dapat digunakan sebagai pengembangan teknologi dalam aplikasi pemesanan makanan pada ETU polinema menggunakan sistem drive thru, dimana dalam aplikasi tersebut dapat memesan sebuah makanan sekaligus juga melakukan pembayaran dan mengetahui lokasi toko dalam gps yang dituju dalam pengambilan pesanan. Maka dalam penelitian ini diusulkan "Rancang Bangun Sistem Komunikasi Data Pemesanan Pada Drive Thru Toko Roti ETU Polinema Berbasis Android",. Hasil dari penelitian ini semoga dapat membuat sebuah rumah makan/ toko dapat dengan mudah melakukan sebuah transaksi pemesanan melalui sistem aplikasi internet.

\section{METODE}

\section{A. Komunikasi Data}

Komunikasi data adalah pertukaran data antara dua perangkat atau lebih melalui media transmisi misalnya seperti kabel. Untuk bisa terjadinya data komunikasi, perangkat harus saling berkomunikasi atau terhubung menjadi sebuah bagian dari sistem komunikasi, yang terdiri atas kombinasi dari hardware (peralatan fisik atau keras) dan perangkat software (program). Efektivitas sistem komunikasi data tergantung pada empat karakteristik yang mendasar, yaitu pengiriman, akurasi, ketepatan waktu dan juga jitter. Atau bisa juga definisi komunikasi data adalah proses pengiriman dan penerimaan data secara elektronik dari dua atau lebih alat yang terhubung kedalam sebuah network (jaringan) melalui suatu media. Karakteristik dasar komunikasi data, diantaranya sebagaimana di bawah ini:

1. Pengiriman - sistem harus mengirimkan data ke tujuannya. Lalu data harus diterima oleh perangkat yang dimaksudkan atau pemakai, dan juga hanya oleh perangkat atau pemakai.

2. Akurasi - sistem harus memberikan data, tentunya yang akurat. Data yang telah diubah dalam transmisi dan meninggalkan sumber, data yang tak di koreksi tentunya tidak dapat digunakan.
3. Ketepatan waktu/tepat waktu - sistem harus mengirimkan data pada waktu yang tepat. Terlambat dikirimkannya data maka tak akan berguna. Dalam kasus video serta audio, pengiriman waktu yang tepat berarti memberikan data seperti yang diproduksi/seperti aslinya, dalam urutan yang sama ketika dibuat dan tanpa penundaan yang signifikan. Semacam ini disebut dengan pengiriman transmisi real-time.

4. Jitter - mengacu kepada variasi waktu kedatangan paket. Yaitu keterlambatan yang tidak merata dalam pengiriman paket audio maupun video. Sebagai contohnya, kita asumsikan misalnya bahwa paket video yang dikirim setiap 3D ms. Jika dari beberapa paket datang dengan delay 3D ms dan yang lain dengan delay 4D ms, maka akan menghasilkan kualitas yang tak merata dalam video itu.

\section{B. $P H P$}

PHP adalah bahasa pemrograman script server-side yang didesain untuk pengembangan web. Selain itu, PHP juga bisa digunakan sebagai bahasa pemrograman umum (wikipedia). PHP di kembangkan pada tahun 1995 oleh Rasmus Lerdorf, dan sekarang dikelola oleh The PHP Group. PHP disebut bahasa pemrograman server side karena PHP diproses pada komputer server. Hal ini berbeda dibandingkan dengan bahasa pemrograman client-side seperti JavaScript yang diproses pada web browser (client).

\section{Laragon}

Laragon adalah universal development environment untuk PHP, Node.js, Python, Java, Go, Ruby, yang portable, terisolasi, cepat, ringan, dan mudah dipakai. Laragon memilik banyak fungsi seperti:

1. Pretty URLs:

Dengan memakai laragon kita bisa mengakses project lewat app.test daripada menggunakan localhost/app.

2. Portable:

Folder Laragon bisa dipindah-pindah tanpa perlu merusak sistemnya.

3. Isolated:

Sistem Laragon terisolasi dari sistem operasi yang kita miliki sehingga apapun yang kita lakukan dengan Laragon tidak akan mempengaruhi komputer lokal.

4. Easy Operation:

Laragon sudah mengotomatiskan banyak konfigurasi yang kompleks sehinga kita "tinggal pakai" saja. Kita bisa menambah versi baru dari PHP, Python, Ruby, Java, Go, Apache, Nginx, MySQL, PostgreSQL, MongoDB, atau yang lainnya tanpa kesulitan yang berarti dan tanpa merusak sistem yang sudah ada.

5. Modern \& Powerful

Laragon memiliki arsitektur modern yang cocok untuk dipakai mengembangkan aplikasi web mdoern. Kita bisa menggunakan Apache \& Nginx sekaligus.

\section{QrCode}

Kode QR adalah suatu jenis kode matriks atau kode batang dua dimensi yang dikembangkan oleh Denso Wave, sebuah divisi Denso Corporation yang merupakan bentuk evaluasi 
dari barcode yang biasanya dapat di lihat pada sebuah produk. Kode QR berbentuk kotak atau persegi berwarna hitam dengan tampilan yang sangat rumit guna untuk mempersulit pengguna untuk membacanya melainkan penggunakan smartphone atau perangkat lain yang mendukung aplikasi pembaca QR. Pada awalnya QRcode digunakan untuk pelacakan bagian dari sepeda motor. Sehubungan dengan perkembangan zaman maka QRcode sekarang digunakan dalam kontek yang sangat luas, termasuk aplikasi - aplikasi pada perangkat yang mendukung pembacaan QRcode.

\section{E. Android Studio}

Android Studio merupakan Integrated Development Environment (IDE) resmi untuk pengembangan aplikasi Android, berdasarkan IntelliJ IDEA. Android berubah menjadi platform yang begitu cepat dalam melakukan inovasi. Hal ini tidak lepas daгi pengembangan utama dibelakangnya, yaitu Google. Googlelah yang mengakuisisi Android dan kemudian membuatkan sebuah platform.

\section{F. Quality of Service (QoS)}

Quality of Service (QoS) adalah kemampuan suatu elemen jaringan, seperti aplikasi jaringan, host, atau router untuk memiliki tingkatan jaminan bahwa elemen jaringan tersebut dapat memenuhi kebutuhan suatu layanan.Terdapat beberapa parameter Quality of Service (QoS), yaitu sebagai berikut:

\section{Bandwidth}

Bandwidth adalah luas atau lebar cakupan frekuensi yang digunakan oleh sinyal dalam medium transmisi.

2. Throughput

Throughput adalah kemampuan sebenarnya suatu jaringan dalam melakukan pengiriman data. Biasanya throughput selalu dikaitkan dengan bandwidth dalam kondisi yang sebenarnya. Throughput dirumuskan pada persamaan (1) berikut:

$$
\text { Troughput }=\frac{\text { Packed } \text { Received }(\mathrm{kb})}{\text { Times } \text { Transmitted }(\mathrm{s})}
$$

Adapun standar Throughput menurut TIPHON adalah sebagai berikut:

TABEL 1

STANDAR THROUGHPUT MENURUT TIPHON

\begin{tabular}{ccc}
\hline Kategori Throughput & Throughput & Indeks \\
\hline Bad & $0-338 \mathrm{kbps}$ & 0 \\
\hline Poor & $338-700 \mathrm{kbps}$ & 1 \\
\hline Fair & $700-1200 \mathrm{kbps}$ & 2 \\
\hline Good & $1200-2,1 \mathrm{Mbps}$ & 3 \\
\hline Excelent & $>2,1 \mathrm{Mbps}$ & 4 \\
\hline
\end{tabular}

3. Jitter

Jitter adalah variasi atau perubahan latency dari delay atau variasi waktu kedatangan paket. Jitter juga didefinisikan sebagai gangguan pada komunikasi digital maupun analog yang disebabkan oleh perubahan sinyal karena referensi posisi waktu. Adapun standar jitter menurut TIPHON adalah sebagai berikut:
TABEL 2

STANDAR JITTER MENURUT TIPHON

\begin{tabular}{ccc}
\hline Kategori Jitter & Jittert & Indeks \\
\hline Poor & $125-225 \mathrm{~ms}$ & 1 \\
\hline Medium & $75-125 \mathrm{~ms}$ & 2 \\
\hline Good & $0-75 \mathrm{~ms}$ & 3 \\
\hline Perfect & $0 \mathrm{~ms}$ & 4 \\
\hline
\end{tabular}

\section{Packet Loss}

Packet loss adalah parameter yang menggambarkan suatu kondisi yang menunjukkan jumlah total paket yang hilang. Paket yang hilang ini dapat terjadi karena collision dan congestion pada jaringan. Packet Loss dihitung berdasarkan persentase paket yang berhasil dikirim, dirumuskan sebagai berikut:

Packed loss $=\frac{(\text { Packed transmitted }- \text { Packed received })}{\text { Packed } \text { transmitted }} \times 100 \%$

Adapun standar packet loss menurut TIPHON adalah sebagai berikut:

TABEL 3

STANDAR PACKET LOSS MENURUT TIPHON

\begin{tabular}{ccc}
\hline Kategori Packet Loss & Packet Loss & Indeks \\
\hline Poor & $>25 \%$ & 1 \\
\hline Medium & $12-24 \%$ & 2 \\
\hline Good & $3-14 \%$ & 3 \\
\hline Perfect & $0-22 \%$ & 4 \\
\hline
\end{tabular}

A. Prosedur Pengoperasian

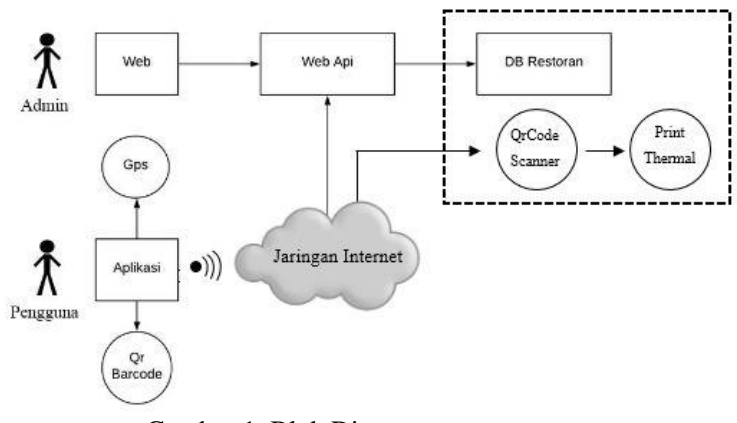

Gambar 1. Blok Diagram perencanaan

Berdasarkan blok diagram perencanaan dapat dijelaskan sebagai berikut:

Ketika membuka aplikasi dimana konsumen dapat memilih menu untuk dilakukan order dan juga terdapat Gps yang dapat menunjukkan lokasi rumah makan/ toko tersebut, ketika konsumen selesai melakukan pesanan dan pembayaran awal maka otomatis akan mendapatkan Qrcode hasil dari pemesanan tersebut. Data pesanan akan terkirim kepada database webserver toko menggunakan web api sebagai sistem pengirim data. Restoran akan mendapatkan order dari konsumen dan nantinya ketika konsumen datang, konsumen hanya perlu menscan Qrcode yang telah didapat dari proses pembelian tadi di alat Qrcode Scanner yang telah disiapkan pada loket pengambilan barang dimana qrcode itu bertujuan untuk mengetahui apakah pesanan itu merupakan benar milik konsumen itu sendiri, setelah itu konsumen hanya perlu mengambil makanan yang sudah disiapkan. 


\section{HASIL DAN PEMBAHASAN}

A. Pengujian Tampilan Sebelum Melakukan Komunikasi

Pada tampilan ini user/ customer diharuskan login kedalam aplikasi terlebih dahulu jika ingin melakukan proses pemesanan.

1. Tampilan Login

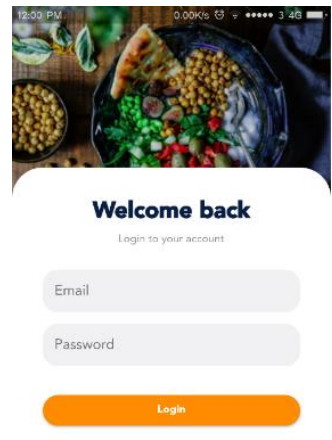

Gambar 2. Tampilan login

2. Tampilan Register

Pada Tampilan ini jika user tidak mempunyai akun aplikasi dapat membuat akun terlebih dahulu sebelum melakukan proses login dan pemesanan.

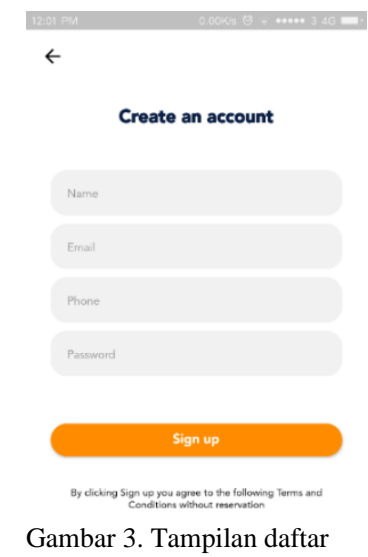

3. Tampilan Layar Utama

Tampilan layar utama adalah halaman pertama dan sekaligus sebuah halaman yang menampilkan jenis jenis kue yang ada di ETU Polinema.

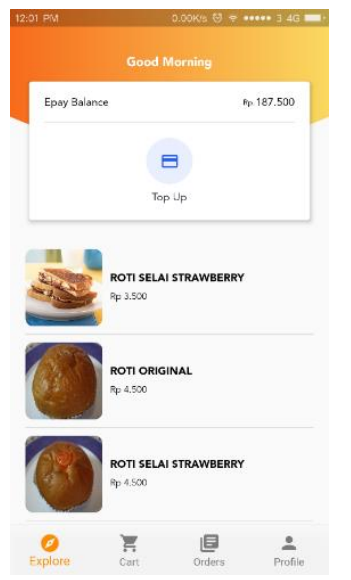

Gambar 4. Tampilan Layar Utama
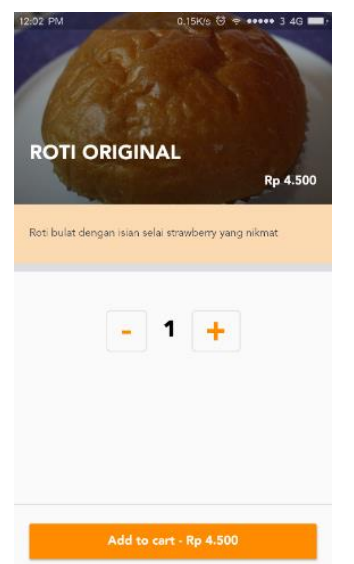

Gambar 5. Tampilan tambah produk

4. Tampilan Menu Top - Up saldo

Pada tampilan menu saldo ini user dapat melakukan pengisian saldo jika saldo kurang untuk melakukan pembelian.

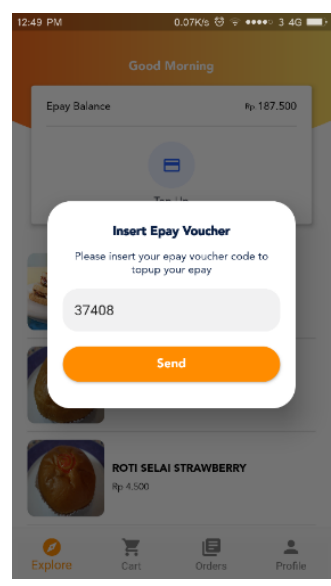

Gambar 6.Tampilan top-up saldo

5. Tampilan Layar Keranjang

Pada tampilan keranjang ini menunjukan daftar pesanan user dalam layar ini user dapat melakukan jenis pembayaran 
Jurnal Jaringan Telekomunikasi (Jurnal Jartel), E-ISSN: 2654-6531, P-ISSN: 2407-0807 Vol. 10, No. 3 (2020) 144-149

ditempat / Cash atau E-Pay, jika user ingin menambahkan produk lagi dapat menekan menu add more items.

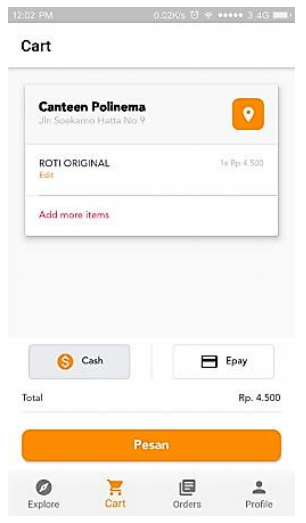

Gambar 7. Tampilan layar keranjang

6. Tampilan layar Pembelian

Pada Tampilan layar pembelian menunjukan pesanan yang user lakukan sudah diterima oleh admin.

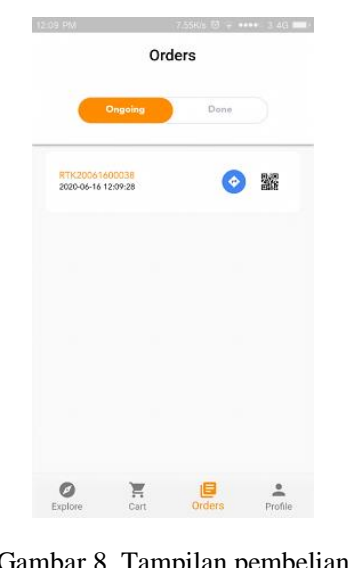

7. Tampilan layar Pembelian Selesai

Pada Tampilan ini menunjukan bahwa pesanan yang dilakukan user sudah diambil oleh user.

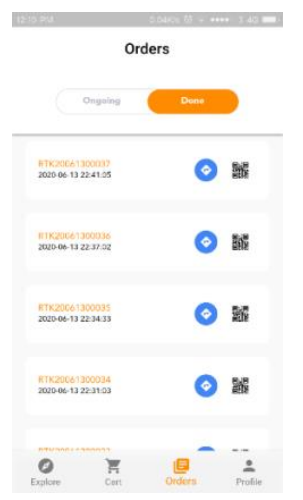

Gambar 9. Tampilan layar pembelian selesai

8. Tampilan Kotak Qr Code

Pada tampilan kotak Qrcode menunjukan bahwa pesanan sudah diterima admin dan user mendapatkan Qrcode untuk dapat dilakukan scan pada saat pengambilan pesanan.

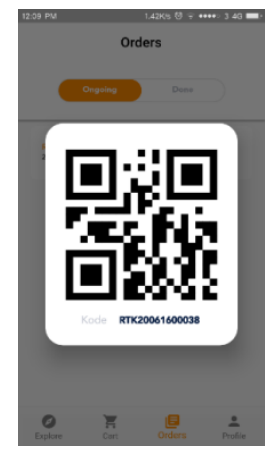

Gambar 10. Tampilan Qrcode

9. Tampilan Layar Profil dan Log Out

Pada tampilan ini menunjukan profil user dengan adanya nama user dan sekaligus menu keluar dari aplikasi.

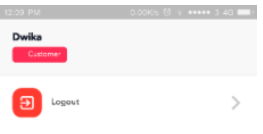

Gambar 10. Tampilan log out

\section{B. Pengujian Jarak Baca QrCode}

TABEL 4

MELAKUKAN PENGUJIAN JARAK BACA QRCODE

\begin{tabular}{cccccccccc}
\hline \multicolumn{8}{c}{ Jarak $(\mathrm{cm})$} \\
\hline $\begin{array}{c}\text { Parame } \\
\text { ter }\end{array}$ & 10 & 20 & 30 & 40 & 50 & 60 & 70 & 80 & $\begin{array}{c}\text { Rata } \\
\text {-rata }\end{array}$ \\
\hline $\begin{array}{c}\text { Delay } \\
\text { (s) }\end{array}$ & 1,2 & 1,7 & 1,5 & 2,0 & 3,5 & 4,1 & 4,2 & 5,3 & \\
\hline
\end{tabular}

Tabel 4 menjelaskan percobaan jarak pindai Qrcode dimana melakukan percobaan dengan radius $10 \mathrm{~cm}, 20 \mathrm{~cm}, 30 \mathrm{~cm}$, $40 \mathrm{~cm}, 50 \mathrm{~cm}, 60 \mathrm{~cm}, 70 \mathrm{~cm}$, dan $80 \mathrm{~cm}$. Dengan hasil Qrcode dapat terbaca tetapi memiliki delay yang berbeda-beda, ratarata delay sebesar $2,98 \mathrm{~s}$.

\section{Pengujian $Q o S$}

TABEL 5

PENGUJIAN QOS DENGAN PROVIDER INDOSAT

\begin{tabular}{cccc}
\hline No. & Delay & Trough put & Paket loss \\
\hline 1 & 7.782395 & & 0 \\
2 & 0.000432 & & 0 \\
3 & 0.000849 & 8953,14 & 0 \\
4 & 0.059452 & & 0 \\
5 & 0.000691 & & 0 \\
\hline Rata-rata & 7.843819 & & \\
\hline
\end{tabular}

Tabel 5 merupakan 5 sampel dari beberapa paket yang akan dicari rata-rata dari delay, paket tersebut diambil pada wireshark yang terdiri dari beberapa paket ketika melakukan pengujian langsung terdapat peningkatan delay yg lama 
dengan nilai $7.782395 \mathrm{~s}$. Hasil rata-rata delay pada provider three sebesar 7.843819s dengan nilai troughput 8953,14.

TABEL 6

PENGUJIAN QOS DENGAN PROVIDER TELKOMSEL

\begin{tabular}{cccc}
\hline No. & Delay & Trough put & Paket loss \\
\hline 1 & 0.001005 & & 0 \\
2 & 0.068331 & & 0 \\
3 & 0.001115 & 3891,16 & 0 \\
4 & 0.000012 & & 0 \\
5 & 0.051303 & & 0 \\
\hline Rata-rata & 0.121766 & & \\
\hline
\end{tabular}

Tabel 6 merupakan 5 sampel dari beberapa paket yang akan dicari rata-rata dari delay, paket tersebut diambil pada wireshark yang terdiri dari beberapa paket ketika melakukan pengujian langsung. menjelaskan bahwa terdapat peningkatan delay yg lama dengan nilai 0.068331 s. Hasil rata-rata delay pada provider three sebesar 0.121766 s dengan nilai troughput 3891,16 .

TABEL 7

PENGUJIAN QOS DENGAN PROVIDER AXIS

\begin{tabular}{cccc}
\hline No. & Delay & Trough put & Paket loss \\
\hline 1 & 0.000670 & & 0 \\
2 & 0.078799 & & 0 \\
3 & 0.000857 & 9106,85 & 0 \\
4 & 0.000015 & & 0 \\
5 & 0.069889 & & 0 \\
\hline Rata-rata & 0.150230 & & \\
\hline
\end{tabular}

Tabel 7 merupakan 5 sampel dari beberapa paket yang akan dicari rata-rata dari delay, paket tersebut diambil pada wireshark yang terdiri dari beberapa paket ketika melakukan pengujian langsung. Tabel ini menjelaskan bahwa terdapat peningkatan delay yg lama dengan nilai 0.078799 s. Hasil ratarata delay pada provider three sebesar 0.150230 s dengan nilai troughput 9106,85.

TABEL 8

PENGUJIAN QOS DENGAN PROVIDER THREE

\begin{tabular}{cccc}
\hline No. & Delay & Trough put & Paket loss \\
\hline 1 & 0.000205 & & 0 \\
2 & 0.000450 & & 0 \\
3 & 0.000308 & 12498 & 0 \\
4 & 0.250572 & & 0 \\
5 & 0.059797 & & 0 \\
\hline Rata-rata & 0.311332 & & \\
\hline
\end{tabular}

Tabel 8 merupakan 5 sampel dari beberapa paket yang akan dicari rata-rata dari delay, paket tersebut diambil pada wireshark yang terdiri dari beberapa paket ketika melakukan pengujian langsung. Gambar 4.15 menjelaskan bahwa terdapat peningkatan delay yg lama dengan nilai $0,250572 \mathrm{~s}$. Hasil rata-rata delay pada provider three sebesar $0.311332 \mathrm{~s}$ dengan nilai troughput 12498 .

\section{KESIMPULAN}

Berdasarkan perancangan alat dan hasil pengujian yang dilakukan pada penelitian dengan judul Rancang Bangun Sistem Komunikasi Data Pemesanan Pada Drive Thru Toko
Roti ETU Polinema Berbasis Android dapat disimpulkan bahwa:

1. Aplikasi andorid ini digunakan untuk sistem pemesanan drive thru secara online, dimana user diharuskan untuk mendaftar dulu menjadi member dari toko roti ETU Polinema, setelah itu user dapat membeli roti sesuai produk yang ada pada aplikasi, terdapat 2 sistem pembayaran dimana user dapat melakukan pembayaran tunai ataupun e-pay. Saldo e-pay dapat dibeli pada admin dengan cara mentransfer uang kepada rekening ETU Polinema. Ketika pembeli sudah melakukan pembayaran, user akan secara langsung mendapatkan Qrcode yang berfungsi untuk pengecheckan data pembelian.

2. Pengambilan data delay, troughput serta paket loss menggunakan aplikasi wireshark secara langsung, pengambilan data menggunakan 4 provider yaitu indosat, telkomsel, axis dan three. Setiap provider mempunyai nilai rata-rata delay yang berbeda beda, dimana delay terkecil yaitu telkomsel sebesar 0.121766 s dan delay terbesar pada provider indosat yaitu 7.843819s.

3. Pengujian dalamm engetahui jarak baca Qrcode aplikasi dicoba dalam radius $10 \mathrm{~cm}, 20 \mathrm{~cm}, 30 \mathrm{~cm}$, $40 \mathrm{~cm}, 50 \mathrm{~cm}, 60 \mathrm{~cm}, 70 \mathrm{~cm}$, dan $80 \mathrm{~cm}$, setiap tahap memiliki delay yang berbeda-beda. Hasil pengujian mendapatkan nilai rata-rata delay jarak baca Qrcode sebesar 2,98s.

\section{REFERENSI}

[1] A. G. Putra, W. Wibisono, And H. T. Ciptaningtyas, "Rancang Bangun Aplikasi Android Virtual Shopping Berbasis Qr Code Dan Global Positioning System Untuk User Bergerak," J. Tenik Pomits, Vol. 1, No. 1, Pp. 1-5, 2012.

[2] I. R. Hendratno Rhuby, "Perancangan Sistem Komunikasi Data Wireless Pada Reservasi Restoran Melalui Web," Vol. 5, No. 1, 2014.

[3] B. Yulianto, L. C. Dewi, And O. Wijaya, "Peran Website Restoran Terhadap Daya Tarik Konsumen Online," Comtech Comput. Math. Eng. Appl., Vol. 5, No. 2, P. 1096, 2014.

[4] I. O. Widjoyo, L. J. Rumambi, And Y. S. Kunto, "Analisa Pengaruh Kualitas Layanan Terhadap Kepuasan Konsumen Pada Layanan Drive Thru Mcdonald's Basuki Rahmat Surabaya," J. Manaj. Pemasar., Vol. 1, No. 1, Pp. 1-12, 2013. 